\title{
ANILLOS INÉDITOS DE TIPO EGIPCIO PROCEDENTES DE ANDALUCÍA
}

\author{
UNPUBLISHED EGYPTIAN-LIKE RINGS FROM ANDALUSIA
}

por

\author{
MARÍA ANTONIA GARCÍA MARTÍNEZ ${ }^{1}$
}

\section{CÁDIZ (fig. 1)}

Este anillo procede de la provincia de Cádiz, donde forma parte de una colección particular. Mide 2,4 $\mathrm{cm}$ de longitud por $0,9 \mathrm{~cm}$ de anchura. Sólo se ha conservado su chatón de plata, en forma de cartela egipcia rodeada por una incisión a modo de orla.

En sentido horizontal aparece en ella grabado un desfile de deidades orientadas hacia la diosa Maat ${ }^{2}$, a la izquierda que, sedente y coronada por el disco solar, eleva un brazo hacia el cortejo. La pluma $m 3^{`}{ }^{\prime} t$, situada a su espalda, identifica a la diosa representante de la verdad, la justicia y el equilibrio. Probablemente haya que reconocer el mismo símbolo, muy estilizado, en su mano izquierda, adelantada en señal de bienvenida o de bendición hacia la comitiva.

Es ésta presidida por un ureo coronado con el disco solar, seguido de un halcón tocado con el mismo símbolo, que sostiene el látigo $n h h$. Tras ellos, ocupando el centro del grupo que avanza, aparece una figura humana, sin duda un monarca ya que la simbología de todos los componentes de la escena está íntimamente relacionada con la realeza egipcia. Adelanta una pierna en actitud de carninar y, dirigiendo su brazo derecho hacia el frente, empuña el cetro $w 3 s$. A continuación otro ureo coronado con el disco es seguido por una esfinge alada sedente con igual tocado sobre su cabeza.

Esta composición evoca el carácter divino de la realeza egipcia. El rey, de acuerdo con las concepciones egipcias, era partícipe de la misma naturaleza que cualquier otra divinidad. Su función terrestre, secundando

1. Universidad Autónoma de Barcelona.

Omitiendo aquí mi opinión personal respecto a la posesión privada de piezas arqueológicas, así como mis sugerencias sobre las posibles soluciones legales para que el hallazgo de las mismas fuese de dominio público y su localización y estudio viables -por reconocer que ninguna de las que puedo concebir garantizaría su total efectividad-he de agradecer sin embargo la amabilidad con que se me ha facilitado el acceso al estudio de estos anillos. La reflexión privada y oficial sobre el valor histórico de estos documentos, insustituible por cualquier otro de tipo material que pueda estimarse para las mismas, razonablemente debiera llevarnos a actitudes en las que el altruismo fuese componente fundamental.

2. Para la transcripción al castellano de los nombres propios egipcios he adoptado aquí la normalización propuesta por $\mathbf{J}$. Padró (1987). 
la celeste de la diosa Maat, era mantener en este mundo el equilibrio que impedía el retroceso al caos inicial del que supuestamente surgió el universo, defendiendo la verdad y la justicia.

Aparece el monarca en esta escena portando el cetro w3s característico de los dioses y precedido de su propio símbolo de dios Horo, de quien se consideraba reencarnación durante su reinado. Este halcón, Horo, sujeta el látigo $n h h$, símbolo de su realeza. Los ureos representan asimismo el poder divino y real, como imagen del ojo sagrado perdido por el dios Re quien, tras haberlo recuperado, lo convirtió en la cobra protectora que aparece en su frente y en la de los faraones.

La esfinge alada hieracocéfala integra la tradicional simbología de la esfinge, cuya forma adoptó la iconografía de varios monarcas y la cabeza y las alas del halcón, con el significado real anteriormente comentado ${ }^{3}$.

Además de los abundantes anillos portadores de escarabeos, se utilizaron en Egipto otros modelos, a menudo de tipo sello. Hay buenos ejemplos de anillos en el ajuar funerario de Tutanjamon (Wilkinson 1971: $130 \mathrm{ss}$ ). Algunos de ellos adoptan la forma de cartucho real simple o doble, habiendo sido tratados de forma muy detallista. Otros, más estilizados y cercanos al chatón en estudio, omiten algunos detalles de la cartela real. A menudo contienen éstos el nombre real escrito en jeroglíficos y, en ocasiones, reproducen la figura de un dios (Wilkinson 1971: 133, $\mathrm{n}^{\mathbf{0}}$ 65) o del monarca en adoración ante distintas divinidades (Wilkinson 1971: 130-131, nn. 56-60), solo o acompañado por otros personajes (Wilkinson 1971: 132-133).

Este mismo tipo de chatón, bien de manufactura egipcia o feno-púnica, ha sido hallado en Cartago (Vercoutter 1945: XXIV, nn. 833, 871 y 874), Marruecos (Ponsich 1967: 33, I, 167, XLVI) y Cerdeña (Pisano 1974: 25, 240, nn. 288-326). En la Península Ibérica contamos con ejemplares como el procedente de Los Villares, en Andújar, Jaén (Contreras 1960: 294-296), con una esfinge alada, los dos que forman parte del Tesoro de La Aliseda, Cáceres, uno de ellos con una escena nilótica (Blázquez 1968: 47C-48A), un chatón hallado en la provincia de Huelva y conservado en una colección particular sevillana, con representación esquemática de divinidades de rostro simiesco, quizás felino (De la Bandera y Marín 1985: 230 ss., XXXII, nº 2) y el anillo de Villaricos, Almería (Padró 1980-85, vol. III: 40-41, LXVI, nº 23.48).

Sin excluir la posibilidad de que pudiera tratarse de un anillo de manufactura fenicia, el estudiado desdoblamiento de la figura real, así como el intencionado intercambio de cetros reales y divinos, muy probablemente se deben a un taller egipcio familiarizado con los detalles más sutiles de las concepciones religiosas egipcias. La pieza es datable entre los siglos VII y VI, teniendo en cuenta el límite cronológico que generalmente ha venido siendo aceptado para la colonización fenicia peninsular. Si bien, dada la relativa frecuencia de hallazgos arqueológicos peninsulares que podrían documentar un desplazamiento de dicha colonización hacia las fechas anteriores transmitidas por las fuentes clásicas, en base a los paralelos de este anillo, su datación puede ser también anterior, ya que se trata de un modelo tradicionalmente repetido en Egipto.

\section{CÁDIZ (fig. 2.)}

El anillo es de plata y mide $2,5 \mathrm{~cm}$ de diámetro. Su chatón tiene $3 \mathrm{~cm}$ de longitud por $1,9 \mathrm{~cm}$ de anchura y $0,3 \mathrm{~cm}$ de grosor. Es conservado por un particular de Cádiz, quien asegura su procedencia de la misma provincia.

Se trata de un aro de sección circular con chatón del mismo tipo que la pieza anterior aunque con anchura considerablemente superior.

Una línea ovalada rodea la siguiente inscripción jeroglífica: $s 33 s t$ tf f3i $H t-h r s 3 s 3 w$ "Isis protege a la portadora del amuleto protector de Hathor", dedicada a la portadora del anillo, que sin duda habría de

3. Ver una referencia a esta simbología real de la esfinge en J. Padró (1980-85: 45-50). 
ser una mujer, según especifica el adjetivo demostrativo $t f$, "esta", utilizado en Época Baja con las mismas funciones de nuestro artículo "la".

La frase evoca a las dos diosas, Isis y Hathor, cuyo fuerte sincretismo aparece bien documentado en Época Baja.

Son muy abundantes los paralelos para este anillo de cartela ancha, típicamente saíta. Aparecen muy frecuentemente en ellos frases invocando la protección de distintas deidades o monarcas (Hall 1913: 283, $\mathrm{n}^{\mathrm{0}}$ 2737; Aldred y otros 1980: 172, $\mathrm{n}^{\mathrm{O}}$ 153). Un anillo conservado en el Louvre, con idéntica forma y similares dimensiones a la pieza en estudio, ofrece una frase igual a la que en ésta aparece (Aldred y otros 1980: $172, \mathrm{n}^{\mathrm{0}}$ 153).

Este es un anillo sin duda manufacturado en Egipto, fechable entre los siglos VII y VI, en base a sus paralelos. La corrección con que han sido tratados sus jeroglíficos y la precisión de signos tales como el determinativo de Isis en forma de huevo-generalmente confundido por los copistas fenicios y aún, en varias ocasiones, por los mismos egipcios de Época Baja con el del disco solar u otro signo redondeado-indican claramente el trabajo de un artesano habituado a reproducir y a leer su propio sistema de escritura.

\section{SEVILLA (fig. 3)}

Este anillo fue comprado por el Museo Arqueológico Provincial de Córdoba en 1930 a D. Juan Torres, quien lo había hallado en el término municipal de Alcalá del Río, Sevilla, según especifica el libro de registro de entrada de piezas de dicho Museo, donde se conserva con el no 5.875 .

La pieza no pudo ser localizada entre los fondos arqueológicos del Museo, por lo que su estudio tiene como base el dibujo y las notas descriptivas que constan en su libro de registro. Sus dimensiones son de $1,4 \mathrm{~cm}$ de diámetro interno y $2,3 \mathrm{~cm}$ de longitud del chatón. El anillo fue trabajado en un tipo de piedra sin especificar.

Se trata de un anillo de aspecto pesado, realizado en una sola pieza de piedra trabajada en forma de aro semicircular de considerable grosor y anchura y sección rectangular que aumenta progresivamente de dimensión hacia los extremos. En el sello, rectangular y de superficie plana, aparecen verticalmente trazados cuatro signos jeroglíficos.

El superior de ellos parece corresponder al signo no X1 de Gardiner (1969), correspondiente al fonema " $t$ ". Sin embargo debe tratarse de una deformación del disco solar, como veremos. A continuación una deidad sentada mirando hacia la izquierda, con facciones zoomorfas que pueden corresponder a las de los dioses Anubis o Set. Le sigue un signo $m n$ y, tras él, el escarabajo $h p r$.

La lectura corresponde a un praenomen real. La gran mayoría de éstos incluye el término $\mathrm{Re}$, alusivo a este dios, pronunciado al final del praenomen del monarca pero escrito en primer lugar, debido a la norma de inversión respetuosa que hizo que los símbolos de deidades precediesen a cualquier otro en una misma palabra. Por ello, la inmensa mayoría de piezas con un praenomen real inscrito ofrecen al disco solar encabezando el mismo.

En este caso, el disco solar Re ha sido deformado, bien por el artesano del anillo, o por la persona que dibujó el mismo en el libro de registro del Museo. Por otra parte difícilmente podría el primer signo representar al fonema " $t$ ", ya que éste hubiese sido dispuesto en segundo lugar, tras la deidad que figura a continuación que, afectada por la misma norma de inversión respetuosa, hubiese ocupado el lugar preferente.

En cuanto a la divinidad de rostro zoomorfo indeterminado reproducida como segundo signo, si observamos el resto de los jeroglíficos que componen el praenomen, llegamos fácilmente a la conclusión de que se trata del dios Set, elemento integrante del nombre del rey Setos I. El praenomen de este monarca fue $M n-M 3^{`} t-R$ ', escrito mediante el disco, la imagen de la diosa Maat o de su pluma simbólica y del signo $m n$. Dos de dichos 
jeroglíficos aparecen en el anillo en estudio, habiendo sido sustituido el de Maat por el del dios Set con el fin de lograr una combinación poco frecuente, aunque en ocasiones procurada, entre el praenomen $M n-M 3^{`}{ }^{\prime}$ $R$ 'del monarca y su nomen, Setos, de forma exactamente igual a la de un paralelo para este grupo, estudiado por Hall (1913: 204, nำ2035) en el Museo Británico.

Pero no es ésta la única combinación buscada en esta inscripción. El praenomen de Tutmosis III, $M n-H p r-R$, ha sido también integrado en ella, mediante la adición del signo hpr en posición final. Ninguna de las dos lecturas altera la disposición de la otra y ambas cuentan con los elementos comunes $M n$ y $R$ `en ambos extremos.

La fusión del nomen con el praenomen de Setos I ha sido ya comentada en un paralelo del Museo Británico. La combinación de los nombres de Setos I y de Tutmosis III fue abundantemente repetida en piezas egipcias (Petrie 1917: XXVI-XXIX, XXXIX; Vercoutter 1945: 134 no 161, 104 n 41) ${ }^{4}$. Aparece también en los ejemplares del Museo Británico (Hall 1913, I: 206, nn. 2052-2055), entre los que asimismo figuran asociaciones de hasta un tercer rey más junto a Setos I y a Tutmosis III (Hall 1913, I: 207, nn. 2068-2071).

Este modelo de anillo fue conocido en Egipto desde finales de la XVIII dinastía (c.1570-1085 a.C.) (Hall 1913, I: XXXV), a la que perteneció Tutmosis III. El segundo nombre real, Setos I, pertenece a la XIX dinastía egipcia (c. 1320-1200 a.C.). Si bien, el nombre de ambos monarcas fue abundantemente repetido en anillos y escarabeos egipcios de Época Baja, a modo de evocación de carácter divino. Este tipo de anillo de apariencia pesada dejó de fabricarse durante el Período Saíta (c. 664-525 a.C.), cuando otros modelos más ligeros fueron adoptados. De nuevo reapareció en Egipto en Epoca Ptolemáica (330-30 a.C.), pero fue preferentemente manufacturado en metales nobles (Hall 1913: 274-275, nn. 2660, 2662 ss.), fallenza (Hall 1913: 275, no 2661 ss.) o marfil (Hall 1913: 277, n-2683). Por ello, la pieza de piedra en estudio es muy probablemente anterior a las épocas Ptolemáica y Saíta. Fue probablemente manufacturada en Egipto aunque, si la deformación del disco solar que aparece en su inscripción no se debiese a la persona que copió la misma en el libro de registro del Museo, habría que pensar en la posibilidad de la copia fenicia defectuosa de un original egipcio, si bien resultaría excepcional el uso de la piedra como material para una reproducción de este tipo de anillo por parte de los colonizadores mediterráneos. Su datación no debe bajar del siglo VIII a.C., sin descartar la posibilidad de una cronología anterior, condicionada a los debatidos límites de la colonización fenicia peninsular, según ha quedado comentado en los párrafos finales dedicados al primer anillo aquí estudiado.

\section{CÁDIZ (fig. 4)}

Se trata de un anillo de plata con un aro en forma de estrecha banda de $2,1 \mathrm{~cm}$ de diámetro y chatón de $1,6 \mathrm{~cm}$ por $1,3 \mathrm{~cm}$ Fue hallado en el fondo de un pozo natural durante la limpieza del mismo, en el término municipal de Sanlúcar de Barrameda, Cádiz, donde es conservado por un particular.

La banda circular del anillo aumenta progresivamente su anchura, hasta alcanzar las indicadas dimensiones del chatón, que consiste en una lámina ovalada. Su contorno aparece decorado con una cenefa a base de breves líneas paralelas. En su centro, una deidad antropomorfa, Isis-Hathor, es precedida por otra zoomorfa en forma de ureo, ambas orientadas hacia la izquierda y coronadas con un disco solar que, en el caso de la primera, está enmarcado por cuernos liriformes.

Isis-Hathor ha sido representada arrodillada en el suelo y sentada sobre sus pies, vistiendo túnica larga con mangas, ajustada en la cintura. Mantiene el brazo derecho extendido a lo largo de sus piernas, mientras que el izquierdo cae junto al cuerpo. Su cabello rodea el cuello, dejando ver una de las orejas. Hathor, la diosa celeste de la fecundidad, el amor, la sensualidad y la alegría, fue representada bien en forma de vaca, bien

4. Además, un par de escarabeos peninsulares en vías de publicación, procedentes de Niebla y de Cádiz respectivamente (García Martínez e.p.). 
en forma de mujer con la cabeza de este animal, o con cabeza humana y orejas de novilla asomando entre su pelo y coronada con el tocado descrito en este anillo. Es esta última imagen la que aquí se ha deseado evocar, aunque debido a las reducidas dimensiones de los detalles sea imposible distinguir si la oreja es humana o animal. Su personalidad quedó asimilada en Época Baja a la de la diosa Isis, madre de Horo en la tríada Osiriana. Las características iconográficas de ambas fueron mezcladas, siendo frecuentemente repetidos temas como el de la vaca Hathor amamantando al hijo de Isis, Horo, en forma de ternero u otros que evidencian el sincretismo.

La cobra que precede a Hathor-Isis fue símbolo en Egipto de varias diosas, en especial de Uadyet. Pero esta divinidad fue a menudo asimilada a Hathor en el mito del ojo sagrado de Re transformado en el ureo que las identifica, cuya función protectora ha sido anteriormente aludida en relación con el anillo no 1 . En la parte inferior del chatón el fonema "t" aparece inscrito dos veces, indicando la terminación femenina de los nombres de ambas diosas. El suelo ha sido representado en la escena mediante pequeños trazos de aspecto vegetal que evocan la marisma del Nilo, componente esencial en la mitología isíaca. Tras la diosa antropomorfa se ha dispuesto una orla en forma de cadena de rizos u ondas.

Éste es un anillo de manufactura púnica, de tipo IX de acuerdo con la clasificación de Boardman (1970: 212-214). Es fechable entre los siglos V y IV a.C. y aparece en contextos mediterráneos de Cerdeña (Pisano 1974: 25 y 53; Usai 1981: 39, III, nn. 1-2), Sicilia (Becatti 1955: H3), Cartago (Gauckler 1915: 531, nn. 6-36) y la Península Ibérica (De la Bandera y Marín 1985: 1ss., nota 10).

En escarabeos egipcios en los que una divinidad sin tocado distintivo que la caracterice, a veces sedente, fue asociada a una cobra, la pareja ha sido interpretada como Uadyet acompañada por el reptil que la identifica (Petrie 1925: 28, XV, XVII, XVIII, nn. 1056, 1319 y 1428). Sin embargo, el tocado dispuesto sobre la cabeza de la divinidad del anillo de Sanlúcar de Barrameda es el característico de Isis-Hathor, aunque los cuernos liriformes han sido muy superficialmente marcados y apenas se aprecian. Por otra parte, el signo " $t$ " duplicado que aparece bajo la escena del anillo gaditano parece indicar la terminación de dos nombres femeninos, por lo que quizás debiésemos interpretar a sus dos figuras como diosas diferentes, Hathor-Isis y quizás Uadyet.

De cualquier modo, el artesano púnico autor de este anillo pudo haber copiado ciertos elementos iconográficos de algún prototipo egipcio, olvidando otros, $o$, por el contrario, añadiendo y mezclando algunos, por lo que no podríamos precisar la exacta intención de esta escena.

Una figura femenina en similar postura a la de la pieza en estudio, precedida de un motivo vertical anterior indefinido, grabada en un escarabeo púnico de Cartago fechado entre los siglos IV y III, quizás intente expresar la misma idea que el escarabeo gaditano (Vercoutter 1945: 220, nํ577).

\section{SEVILLA (fig. 5)}

Sus dimensiones son $2 \mathrm{~cm}$ de diámetro máximo, con chatón de $1,8 \mathrm{~cm}$ por $1,3 \mathrm{~cm}$. Es de procedencia andaluza sin precisar y forma parte de una colección particular de Sevilla. La forma de anillo y chatón es exactamente igual a la de la pieza aquí estudiada con el no 3 . También en ésta aparece una orla rodeando al óvalo del chatón, a base de pequeños trazos paralelos levemente curvados. Un segundo ornamento interior a éste, en forma de dos ramas simétricas con sus brazos o flores dirigidos hacia adentro, ha sido dispuesto a ambos lados de dos figuras centrales que representan a los dioses Isis y Horo.

Isis, en pie y mirando hacia la izquierda, carece de tocado distintivo. Su cabello ha sido indicado del mismo modo que el de Hathor-Isis en el citado anillo anterior $\mathrm{n}^{\mathrm{Q}} 3$, aunque ocultando en este caso la oreja de la diosa. Su brazo izquierdo está flexionado hacia el pecho, mientras que el derecho rodea al hijo, Horo. Permanece éste en pie mirando hacia su madre, con el brazo izquierdo dirigido hacia ella y el derecho a lo largo de su cuerpo. Ambos visten túnica larga sujeta en la cintura, con mangas cortas y adornadas mediante pliegues en sentido transversal. 
Las ramas que flanquean a la pareja aluden probablemente a la vegetación del Delta del Nilo, donde Horo fue escondido por Isis con el fin de protegerle de la agresividad de Set y sus partidarios, antes de su mayoría de edad, durante la cual protagonizó el episodio de la venganza de la muerte de su padre Osiris.

Se trata de un anillo fechable entre los siglos V y III, cuya temática tratada en estilo helenizante cuenta con numerosos paralelos entre los escarabeos de manufactura púnica. Esta variante con ambos dioses en pie es conocida en Cartago (Vercoutter 1945: 216-218, nn. 559-569; 240-241, nn. 656-660; 248-249, nn. 691-693), Ibiza (Boardman 1984: VII-X, nn. 42-57) y la Península Ibérica (Padró 1980-85, II: 36 ss., XXXVI, no 07.03; III: 13-14, LXXIII, $\left.n^{0} 23.09\right)^{5}$. La escena conserva el simbolismo y la morfología egipcios, si bien carece de algunos de los detalles iconográficos que aparecen en las reproducciones púnicas, tales como el tocado de los dioses, por lo que no podría excluirse la posibilidad de que el anillo hubiese sido manufacturado durante los primeros años de dominio romano peninsular.

\section{BIBLIOGRAFÍA}

ALDRED, C. y otros (1980): El Egipto del Crepúsculo. Madrid, Editorial Española.

BECATTI, G. (1955): Oreficerie Antiche delle Minoiche alla Barbariche. Roma.

BLÁZQUEZ, J.M. (1968): Tartessos y los Orígenes de la Colonización Fenicia en Occidente. Salamanca.

BOARDMAN, J. (1970): Greek Gems and Finger Rings. Early Bronze Age to Late Classical. Londres. (1984): Escarabeos de Piedra procedentes de Ibiza. Madrid.

CONTRERAS, R. (1960): "Notas sobre las piezas más interesantes ingresadas en el Museo en 1960. Sortija egiptizante de Los Villares de Andújar", Oretania II, 6.

DE LA BANDERA, M.L. y MARÍN, M.C. (1985): "Sortijas ibéricas de imitación fenicio-púnica", Rivista di Studi Fenici XIII, 2.

GARCÍA MARTÍNEZ, M.A. (e.p.): Documentos Prerromanos de Tipo Egipcio de la Vertiente Atlántica Hispano-Mauritana. Montpellier.

GARDINER, A. (1969): Egyptian Grammar being an Introduction to the Study of Hieroglyphs ( $3^{\mathrm{a}}$ ed.). Londres.

GAUCKLER, P. (1915): Nécropoles Puniques de Carthage, II. París.

HALL, H.R. (1913): Catalogue of Egyptian Scarabs, Etc., in the British Museum. Volume I. Royal Scarabs. Londres.

PADRÓ, J. (1980-85): Egyptian-Type Documents from the Mediterranean Littoral of the Iberian Peninsula before the Roman Conquest, 3 vols. Leiden.

- (1987): "La transcripción castellana de los nombres propios egipcios", Aula Orientalis 5: 107-124.

PETRIE, W.M.F. (1917): Scarabs and Cylinders with Names. Londres. (1925): Buttons and Design Scarabs. Londres.

PISANO, Q. (1974): I Gioielli Fenici di Tharros nel Meseo Nazionale di Cagliari. Cagliari.

PONSICH, M. (1967): "Nécropoles Pheniciennes de la Region de Tanger”, Études e Travauxd'Archéologie Marocaine 3.

USAI, E. (1981): "Necropoli di Monte Luna (Senorbi, Cagliari)", Rivista di Studi Fenici 9.

VERCOUTTER, J. (1945): Les Objets Égyptiens et Égyptisants du Mobilier Funéraire Carthaginois (Bibliothèque Archéologique et Historique XL). París.

WILKINSON, A. (1971): Ancient Egyptian Jewellery. Londres.

5. Ver asimismo los paralelos citados en relación con el anillo de Cádiz anteriormente estudiado con el nํㅜ 3 . 

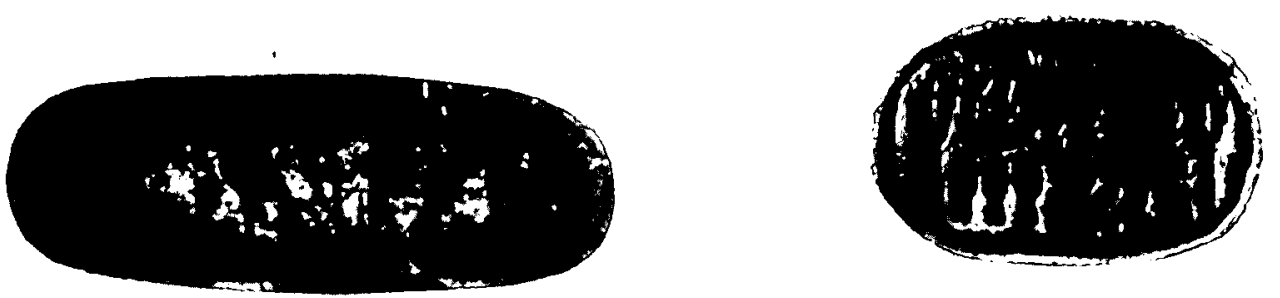

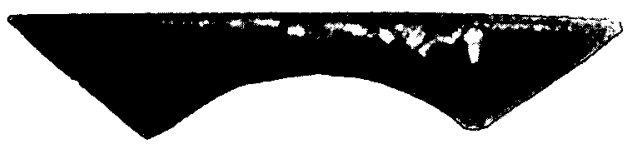

Fig. 1
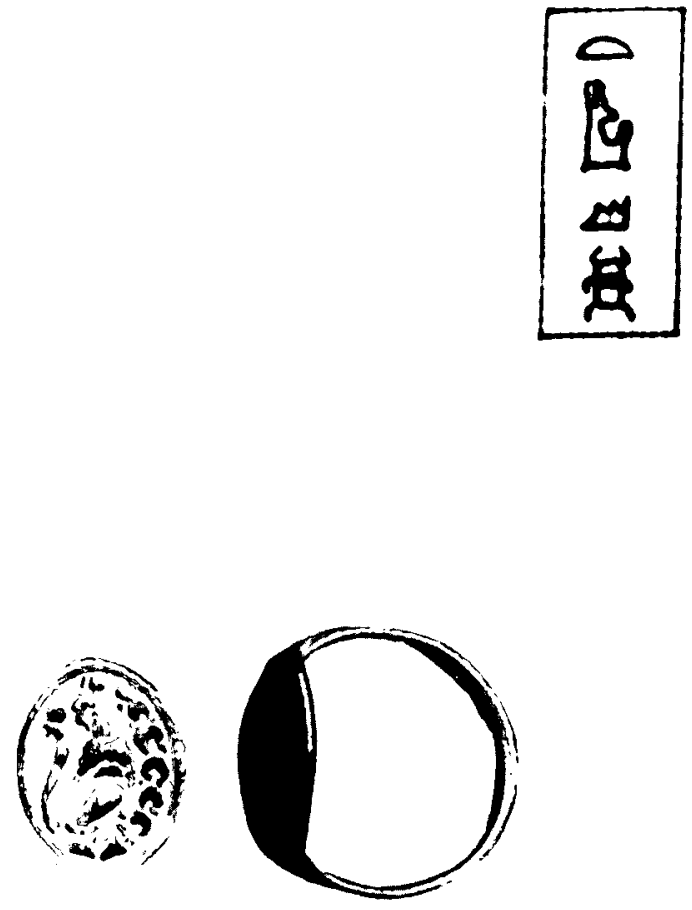

Fig. 4
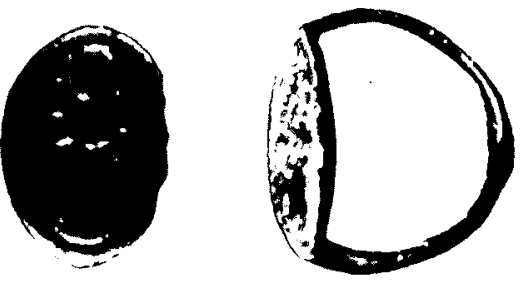

Fig. 5

LÁMINA I 